\title{
Experiencias juveniles en el marco de una resistencia agraria: el caso del Ejido La Sierrita en México*
}

\author{
Youth experiences in the framework of agrarian resistance: the \\ case of Ejido La Sierrita in Mexico
}

Experiências da população jovem no marco de uma
resistência agrária: o caso do Ejido La Sierrita no México

Víctor Daniel García-García**

\section{RESUMEN:}

A partir de recuperar la voz y la experiencia de mujeres y hom-

Palabras clave: bres jóvenes, el reporte expone como se vive la condición de jujuventud rural, ventud en el ejido la Sierrita, comunidad agraria que enfrenta un exclusión social, conjunto de limitantes estructurales y que a la vez enarbola una resistencia en defensa del control de sus recursos naturales, en el Estado de Durango, en México. Al recuperar las narrativas de poblaciones juveniles residentes en el ejido la Sierrita, se observa que actualmente están desarrollando procesos de agenciamienderecho al control de los recursos naturales, participación juvenil. to comunitario, el cual se enfrenta con una cultura tradicional propia de los Ejidos en México. Los resultados argumentan que para el caso del ejido la Sierrita, la participación y propuestas para la defensa de la tierra por parte de las poblaciones juveniles, no están siendo aprovechadas para revitalizar y potenciar la resistencia agraria que se tiene en contra de la minera canadiense Excellon.

Este artículo, a modo de reporte de caso, se deriva del acompañamiento organizativo que el autor realizó con la comunidad del Ejido la Sierrita, Municipio de Tlahualilo, Estado de Durango (México), entre los años 2016 y 2018 como organizador comunitario de la organización Proyecto de Derechos Económicos, Sociales y Culturales A.C. Las reflexiones aquí expuestas son responsabilidad única y exclusivamente del autor del presente trabajo.

** Sociólogo (UAM-Azcapotzalco). Politólogo (UNAM, FES-Acatlán). Maestro en Administración (UPVM). Integrante de la Red Nacional de Jóvenes Investigadores del SIJUNAM (México). E-mail: g2vick@yahoo.com. Código Orcid: 0000-0002-2030-2255. 


\begin{abstract}
Based on recovering the voice and experience of young women and men, the report shows how the condition of youth is experience in Ejido La Sierrita, an agrarian community in the State of Durango, Mexico, that faces a set of structural limitations, while at the same time raising resistance in defense of the control of its natural resources. When recovering the narratives of youth populations residing in Ejido La Sierrita, it can be observed that they are currently developing community agency processes, which are confronted with a traditional culture typical of the ejidos in Mexico. The results argue that in the case of the Ejido La Sierrita, the participation and proposals for the defense of the land by youth populations are not being leveraged to revitalize and strengthen the agrarian resistance against the Canadian mining company Excellon.
\end{abstract}

\section{RESUMO}

Baseado na recuperação da voz e da experiência de mulheres e homens jovens, o relatório expõe como se vive a condição de juventude no Ejido La Sierrita, uma comunidade agrária que enfrenta um conjunto de limitações estruturais e que, ao mesmo tempo, levanta uma resistência em defesa do controle de seus recursos naturais, no Estado de Durango, no México. Ao recuperar as narrativas das populações jovens residentes no ejido La Sierrita, é possível observar que atualmente estão desenvolvendo processos de agenciamento comunitário, os quais se confrontam com uma cultura tradicional própria dos ejidos no México. Os resultados argumentam que, no caso do ejido La Sierrita, a participação e as propostas para a defesa da terra das populações jovens não estão sendo aproveitadas para revitalizar e potencializar a resistência agrária existente contra a empresa canadense de mineração Excellon.
Keywords: rural youth, social exclusion, right to control natural resources, youth participation.

Palavras-chave: juventude rural, exclusão social, direito ao controle dos recursos naturais, participação dos jovens. 


\section{Introducción}

Este artículo presenta una reflexión sobre cómo se vive la condición de juventud al interior de una comunidad agraria que enfrenta un conjunto de limitantes y carencias estructurales y que además afronta un conflicto agrario por el derecho al control de sus recursos naturales frente a una empresa transnacional minera canadiense.

El ejido la Sierrita se encuentra ubicado en el estado norteño de Durango, en México. Después de los estados de Sonora y Zacatecas, hasta 2017, era la tercer entidad federativa con más concesiones mineras otorgadas por la Secretaria de Economía, que de acuerdo con la Ley Minera (Cámara de Diputados, 2014), es la instancia gubernamental encargada de generar títulos de concesión para la exploración y explotación de minerales en México.

En México, desde 1992 con la reforma neoliberal al artículo 27 constitucional se ha venido apuntalando una transformación del territorio con miras a atender las necesidades actuales del patrón de acumulación capitalista, en este contexto geopolítico de redistribución territorial neoliberal (López de la Vega, 2016), la propiedad social de la tierra ha venido siendo atacada continuamente, pongamos por ejemplo la reforma a la Ley Minera del año 2014 donde se estableció que la actividad extractivista de exploración y explotación de minerales serán preferentes sobre cualquier otro tipo de actividad dentro de los territorios.

En este marco de violencias estructurales hacia los territorios que por años han sido propiedad de comunidades agrarias e indígenas, el interés se centró en conocer cómo las poblaciones juveniles habitantes en el ejido la Sierrita han participado en la resistencia agraria que su comunidad mantiene en contra de la minera canadiense Excellon Resources, la cual, ha explotado los bienes naturales del ejido desde el año 2004.

Autores como como Castro, Rojas y Ruiz (2008), Perea (2009), Navarro (2015), Corte (2015) y Bartra (2016) han puesto ampliamente en evidencia diferentes aspectos en torno al destacado y relevante papel que tienen las poblaciones juveniles para impulsar, reactivar, reanimar y/o mantener las resistencias comunitarias que han sufrido desgastes, debilitamientos e incluso desánimos debido al largo tiempo en que se han mantenido en lucha contra la reconfiguración estatal de la terri- 
torialidad, la cual utiliza estrategias gubernamentales y empresariales para debilitar y dividir las resistencias comunitarias.

La reflexión de Castro et al. (2008) pone en la mesa de análisis la participación que han tenido los jóvenes mapuches organizados para apoyar las reivindicaciones territoriales de su pueblo indígena; por su parte, Perea (2009) expone cómo las poblaciones juveniles están recuperando el significado amplio de comunidad para generar poder en lo local y, así, construir un interlocutor colectivo fuerte con capacidad de enfrentar al orden político y sus estructuras hegemónicas; Navarro (2015), por su parte, al recuperar la experiencia del Festival de las Resistencias, organizado por el grupo Jóvenes en Resistencia Alternativa, demuestra cómo hay formas alternas a través de las cuales se pueden activar el interés y la integración de personas jóvenes en luchas y resistencias - en este caso, la experiencia recuperada fue la del Consejo de Ejidos y Comunidades Opositoras a la Presa la Parota; Corte (2015), por su lado, analiza como las poblaciones juveniles tuvieron una participación destacable en el Movimiento No al Dragado, que se opuso al megaproyecto que buscó la construcción de un canal en Argentina para atender las necesidades industriales de una empresa petrolera británica; mientras que Bartra (2016) anota que en México actualmente se vive una insurgencia juvenil, esto es, un movimiento amplio de jóvenes que está tratando de articularse no solo para enfrentar las políticas excluyentes de los gobierno neoliberales que se sucedieron en México desde los años ochenta hasta el año 2018, sino también para impulsar un relevo generacional en los movimientos sociales que son mayormente encabezados por gentes de la segunda o tercera edad.

En este marco, los argumentos que se presentan aquí, encuentran su sustento en lo que se denomina narrativas de resistencia ${ }^{3}$ (Vargas, 2016) que jóvenes habitantes del ejido la Sierrita compartieron. Estas narrativas de resistencia permitieron observar que aún y cuando las poblaciones juveniles están en un contexto altamente excluyente, marginal y precarizado, se encuentran generando posicionamientos para colocarse como un actor colectivo central e importante en el

Al usar la categoría de narrativa de resistencia estamos en la posibilidad de observar, ordenar, sintetizar y sistematizar el conjunto de categorías sociales que influyen en las narrativas y posicionamientos de los sujetos de estudio. 
contexto de resistencia que la comunidad del ejido mantiene ante una transnacional canadiense. De relevancia es mencionar que este agenciamiento juvenil incipiente ha tenido que estructurar sus marcos de participación dentro de los parámetros de una cultura tradicional propia de los territorios rurales (Jurado \& Tobasura, 2012), esto es, bajo sistemas patriarcales y adultocéntricos que impiden una inclusión e integración bajo parámetros de igualdad intergeneracional.

Lo anterior no ha sido una limitante para que las personas jóvenes del ejido La Sierrita tengan un interés, casi general, en recuperar el trabajo en la tierra desde una perspectiva amplia, la cual concibe al territorio como un elemento fundamental para re-posicionarse política, económica y culturalmente en un contexto de reorganización territorial neoliberal, el cual, obliga en la mayoría de los casos, a que las generaciones jóvenes en México, migren de los contextos rurales por la falta de oportunidades.

\section{Contexto de la resistencia comunitaria}

México es uno de los países a nivel de Latinoamérica que cuenta con una amplia reserva de bienes naturales, los cuales, desde hace cuando menos treinta años están siendo amenazados por empresas nacionales y extranjeras que buscan explotarlos en términos industriales y comerciales.

Dentro de este contexto, las comunidades se han organizado para enfrentar estas prácticas de despojo múltiple 4 (Navarro, 2015) que encuentran en la "industria extractiva, la construcción de presas, trasvases hídricos, autopistas y vías urbanas, grandes proyectos inmobiliarios, proyectos turísticos, escaleras náuticas, aeropuertos, rellenos sanitarios, centros para el manejo de residuos tóxicos, compra o alquiler masivo de tierras, transgénicos, corredores industriales, plantas de generación de energía geotérmica, nuclear o proyectos eólicos" (Suprema Corte de Justicia de la Nación, 2014, p. 11) su expresión más acabada.

Estos megaproyectos de despojo, en su mayoría se encuentran protegidos "legalmente" por diversas instituciones del Estado, las cuales,

El despojo múltiple hace referencia a "las formas variadas que adopta el capital en un mismo proceso orientado a explotar lo común” (Navarro, 2015, p. 31). 
en la disputa argumentativa para apuntalarlos, recurren a tesis basadas en la idea de "progreso", "desarrollo" y "crecimiento" regional. En este tenor es que López de la Vega (2016) menciona que la reconfiguración estatal de la territorialidad se basa sobre cinco formas particulares, las cuales se pueden observar en la experiencia vivida por las personas ejidatarias en el ejido la Sierrita en el marco de su resistencia. Estás formas son: (1) el uso jurídico-político de la institucionalidad estatal para la redistribución territorial en detrimento de los derechos de las comunidades; (2) el desplazamiento de la población hacia otras zonas en donde existan empleos con la intención de desterritorializar simbólica y materialmente el territorio; (3) el fortalecimiento de grupos de poder que actúan contra la comunidad con la anuencia gubernamental; (4) esquemas neocoloniales de extracción con apoyo estatal; y (5) imposición de lógicas que posibilitan la división al interior de las comunidades.

En este marco, las resistencias comunitarias son la expresión más fehaciente de organización y reivindicación de derechos con la que cuentan comunidades y ejidos para enfrentar tanto las políticas transnacionales de despojo y usurpación de territorios ${ }^{5}$, como para construir territorialidades comunitarias en defensa de la tierra desde ámbitos jurídicos, simbólicos y culturales.

En esta tesitura, el campo de conflicto que han logrado generar las resistencias comunitarias les ha permitido: colocar en la agenda pública sus reivindicaciones políticas y territoriales, las cuales se encuentran vinculadas a una posición cultural, identitaria y en muchos casos étnica; e impulsar repertorios de resistencia y defensa de derechos con los cuales se ha buscado crear marcos colectivos de seguridad comunitaria (García-García, 2018) ${ }^{6}$, que fortalecen las luchas y agencian políticamente a los actores colectivos en resistencia.

\footnotetext{
Se entiende al territorio desde la complejidad que implica mirarlo como una categoría política, cultural, económica, social y de reproducción de la vida. En este marco, el territorio no sólo es un espacio geográfico específico, sino un espacio en donde se articulan una serie de relaciones sociales que generan estructuras materiales y subjetivas particulares, a partir de las cuales se establecen formas de intercambio, diálogo y confrontación que no pueden ser sujetas a una visión normativa hegemónica.

6 Entiendo a la seguridad comunitaria como una institución para construir poder colectivo objetivo y subjetivo que cuestiona e interpela decisiones políticas excluyentes e identidades asignadas por parte de las instituciones hegemónicas de un Estado-Nación,
} 
El ejido la Sierrita es uno de los 56 ejidos $^{7}$ ubicados en el municipio de Tlahualilo, en el estado de Durango. Su fecha de fundación con base en una resolución presidencial data del año 1980, el total de personas ejidatarias reconocidas es de 126 sujetos (Registro Agrario Nacional, 2017). Durango ocupa el tercer lugar a nivel nacional en territorio concesionado a empresas mineas con 3642 concesiones, el cuarto lugar a nivel nacional en explotación de oro y el segundo lugar a nivel nacional en explotación de plata (Servicio Geológico Mexicano, 2015), lo cual lo coloca como la tercer entidad federativa en México en cuanto al valor de la producción minera (Cámara Minera de México, 2015).

En México, aún y cuando la Secretaria de Economía es la encargada de emitir las concesiones mineras, las empresas extractivas que busquen explotar los minerales que se encuentran debajo del subsuelo tienen que llegar a un acuerdo con los propietarios de las tierras que "beneficie a ambas partes". Para el caso del ejido la Sierrita, el Proyecto de Derechos Económicos, Sociales y Culturales (ProDESC) ${ }^{9}$, ha documentado ampliamente cómo la minera canadiense Excellon ha llevado a cabo una serie de prácticas empresariales desleales que han ocasionado que al día de hoy dicha empresa este obteniendo ganancias millonarias a costa de explotar el territorio y recursos naturales del ejido la Sierrita ${ }^{10}$.

La relación desigual entre Excellon y el ejido la Sierrita comenzó en el año 2004, cuando a partir de engaños lograron instalarse en el territorio ejidal ${ }^{11}$. No siendo sino hasta el año 2008 con el acompañamiento

así, para el caso mexicano, la seguridad comunitaria es un tipo particular de cultura política que reivindica saberes e intereses de las comunidades (García-García, 2018).

Con base en la Ley Agraria (Cámara de Diputados, 2016), un ejido en México es una comunidad agraria que cuenta con personalidad jurídica y patrimonio propio y es propietaria de las tierras que les han sido dotadas.

En Durango se encuentran ubicadas empresas mineras de capital destacable, entre estas destacan Industrias Peñoles, Argonaut Gold Corp, First Majestic Resources, Excellon Resourses, las cuales extraen minerales como oro, plata, plomo y el zinc.

9 ProDESC, es una ONG de defensa de derechos humanos que acompaña organizativa y jurídicamente al ejido la Sierrita en su ejercicio de reivindicación de derechos contra la minera canadiense Excellon.

10 A modo de ejemplo, para el segundo trimestre del año 2018, Excellon aumento su producción de extracción de plata de la mina La Platosa en un 120\% (Mineria en línea, 2018).

11 En México existen tres formas de propiedad de la tierra; la social, la privada y la pública. Para el año 2017, la propiedad social, donde se encuentran contemplados los 
de ProDESC, que lograron firmar un contrato de ocupación temporal justo con la minera canadiense, el cual destacó por contener un conjunto de cláusulas no solamente de carácter económicas, sino también sociales y medioambientales, las cuales estaban pensadas para generar oportunidades de desarrollo endógeno ${ }^{12}$, que permitieran la diversificación de actividades económicas y de empleo para la comunidad del ejido (Arias, 2005). A pesar de la anuencia de la comunidad, la empresa minera canadiense incumplió y violó clausulas acordadas, ocasionando que el ejido, dentro del marco del ejercicio de sus derechos, solicitara a la autoridad agraria competente la rescisión del contrato firmado con la empresa, así como el pago de daños derivado de la inobservancia manifiesta del contrato (Ancheita, 2013; Proyecto de Derechos Económicos, Sociales y Culturales, 2013, 2016; RompevientoTV, 2012).

Por tal motivo, desde el año 2012 el ejido la Sierrita mantiene una resistencia comunitaria por el cumplimiento de las cláusulas que se estipularon en el contrato de ocupación temporal de su territorio, así como por las prácticas desleales que la minera canadiense Excellon ha llevado a cabo en su territorio, que sigue siendo explotado y contaminado por dicha empresa canadiense ${ }^{13}$, la cual, hay que mencionarlo, ha recibido apoyo de la embajada canadiense en México, con el objetivo de incidir sobre las autoridades mexicanas (Moore, 2012) y así imponer la lógica neocolonial extractivista que requiere el patrón de acumulación capitalista actual.

\section{Metodología}

Para rastrear las narrativas de resistencia de las poblaciones juveniles, así como para reflexionar teóricamente a partir de los sentires de la población juvenil en resistencia, se recurrió a la metodología investigación acción participativa (Rendón, 2011; Soliz \& Maldonado, 2012);

ejidos y las comunidades representaba el 54\% del territorio nacional (López-Barcenas, 2017).

12 El desarrollo endógeno está pensado para impulsar las capacidades internas de las comunidades que les permita generar proyectos de vida comunitarios horizontales a partir de aprovechar los recursos con los que cuentan en sus respectivos territorios.

13 Con base en entrevistas realizadas a los representantes actuales del ejido la Sierrita, la empresa minera canadiense Excellon ha contaminado las aguas de riego de la zona con arsénico y otros metales pesados como el plomo y el zinc (Peña, 2020). 
con base en lo anterior, se consideró a las y los jóvenes como actores de su propia historia, quienes al entrar en procesos de reflexión, participación y acción colectiva, pudieron identificar, cuestionar, desnaturalizar y reconocer los marcos estructurales en donde desarrollan sus proyectos de vida y tomar decisiones sobre las mismas. Se seleccionó esta metodología en función de que no se buscaban anécdotas o simples testimonios, sino que a partir de generar dinámicas de reflexión colectiva, se intentó que las y los jóvenes participantes realizaran análisis críticos sobre la participación que habían tenido en la resistencia y sobre las posibilidades de actuación que pudieran tener en el corto plazo para mantener la lucha por la defensa de su territorio.

Una parte de los insumos para la argumentación de este artículo se tomó de la información generada por ProDESC. Las narraciones y reflexiones que se recuperan son de mujeres y hombres jóvenes habitantes en el ejido, las cuales se consiguieron a través de entrevistas semiestructuradas a diez jóvenes, la mitad hombres y la otra mitad mujeres, entre los meses de junio a diciembre de $2016^{14}$. Las personas jóvenes que participaron en las sesiones de reflexión (algunas fueron grupales, otras fueron charlas en el ejido, algunas otras en actividades realizadas para el fortalecimiento organizativo) fueron seleccionadas debido a que en el periodo en que se realizó este análisis en particular, tenían una actividad que no las alejaba de su comunidad, por lo mismo el organizador comunitario estaba en la posibilidad de encontrarlos con cierta facilidad, además de que son personas jóvenes que han tenido una presencia directa en la resistencia que aquí se analiza.

Las narrativas de resistencia obtenidas en las sesiones de reflexión se sistematizaron y analizaron bajo los enfoques de derechos humanos, género y juventudes, con lo cual se estuvo en la posibilidad de acercarnos a conocer la percepción y posición que tienen las poblaciones juveniles residentes en el ejido la Sierrita respecto a la resistencia que la comunidad agraria mantiene, así como sus opiniones en torno

14 Es importante mencionar que también se llevaron a cabo entrevistas grupales a personas adultas y al Comisariado Ejidal de la comunidad, con la información compartida por estos actores, el autor estuvo en la posibilidad de entender la lógica y dinámica adultocéntrica y excluyente respecto a las poblaciones juveniles que impera en el ejido la Sierrita y que se expone a lo largo del escrito. 
a sus derechos y a los patrones de exclusión y de subordinación que viven y experimentan en su vida diaria ${ }^{15}$.

En este artículo la categoría analítica de exclusión es relevante, ya que lo que se encontró fue que aún y cuando las personas jóvenes en el ejido la Sierrita han sido un pilar fundamental en la resistencia agraria, siempre y en todo momento están excluidos de algo: de las decisiones políticas, del control de la tierra, de las asambleas comunitarias, de las oportunidades educativas, de las entrevistas para medios de comunicación que se llevan a cabo en su comunidad, entre otros aspectos (Makowski, 2010).

En este marco, la pregunta principal que guio la reflexión fue: ¿cómo se vive la condición de juventud en una comunidad que ha mantenido una resistencia por sus derechos contra una empresa minera transnacional?, en tanto que algunas interrogantes alternas que también contribuyeron al desarrollo del trabajo fueron: ¿qué papel han tomado las personas jóvenes en las acciones de resistencia que ha llevado a cabo el ejido?, ¿qué percepción tienen las y los jóvenes respecto a la tierra y el territorio?, ¿qué marcadores u ordenadores definen las posiciones y/o acciones de las personas jóvenes en el ejido?, ¿de qué forma han impactado las acciones de resistencia que ha llevado el ejido en la construcción de las identidades de los y las jóvenes habitantes en dicho núcleo agrario?.

\section{Narrativas juveniles en un contexto rural y de resistencia}

Como bien lo indica Jurado \& Tobasura (2012), la construcción y eventual descripción de las identidades de los sujetos jóvenes rurales está condicionada por una serie de procesos y contextos en los cuales llevan a cabo su interacción cotidiana, la cual, es aún más compleja en el ejido la Sierrita en función de la resistencia comunitaria que se tiene.

15 Como se verá más adelante, las poblaciones juveniles residentes en el ejido la Sierrita están excluidas de toda posibilidad de participar en la toma de decisiones comunitarias, así mismo se encuentran insertos en dinámicas familiares y estructurales de subordinación, lo cual en términos de construcción de su biografía, obstaculiza su agenciamiento, y en términos colectivos, limita la posibilidad de aportar ideas o recomendaciones para fortalecer la resistencia agraria que mantiene su comunidad. 
Aun y cuando comparto las posiciones que han presentado Kessler (2005), Medina, Urteaga y Bonilla (2013), y Reyes (2015) en torno a que en las ciencias sociales la discusión y análisis sobre las juventudes rurales no han tenido la misma importancia que los debates sobre juventudes urbanas, lo cual ha ocasionado un déficit en su acercamiento, reflexión y entendimiento, para este artículo recupero la propuesta de Dirven (2016) respecto a que más que una "juventud rural”, actualmente tenemos "un mosaico complejo de jóvenes con diferencias de características demográficas, de localidad dónde viven, ocupación, pertenencia étnica, cultural, socioeconómica, edad y género" (p. XI).

Para el caso de las personas jóvenes a las que se refiere este artículo, lo anterior es evidente ya que aún y cuando se encuentran habitando en un contexto geográfico meramente rural, experimentan un intrincado contexto de interacciones y relaciones entre aspectos tradicionales, locales y globales, que a final de cuentas les colocan en una situación incierta en cuanto a su autoreconocimiento como jóvenes rurales. Por lo mismo, comparto la propuesta en torno a que en un mismo espacio social se pueden identificar y reconocer diversas identidades, a través de las cuales podemos registrar "procesos de imposición, subordinación, destrucción y estigmatización" (Pérez, 2015, p. 96), pero además, procesos de agenciamiento de dichas poblaciones juveniles.

Autores como Reguillo (2012), Cerbino (2006) y Vigil (2013) han mostrado como la ausencia de condiciones estructurales satisfactorias en una comunidad son causas de procesos de exclusión, discriminación, estigmatización y marginación, que como consecuencia generan expresiones y procesos de violencias y por supuesto de resistencias. En este tenor, hay que tener presente que el ejido la Sierrita es una comunidad con carencias estructurales e históricas amplias, lo cual impide que las y los jóvenes puedan alcanzar sus intereses y anhelos, así como desarrollar sus capacidades.

En el ejido la Sierrita, la oferta educativa se limita al nivel secundario; no se cuenta con un centro de salud. En cuanto a servicios públicos, no se tiene red de agua potable para las viviendas: el agua se dota por pipas con una regularidad cuestionable; no hay alcantarillado; y tampoco calles pavimentadas. El sistema de alumbrado público es completamente deficiente; tampoco existe un parque recreativo decente, ni centros religiosos; por supuesto, no hay opciones cultu- 
rales, ni deportivas; para poder emplearse o mantener sus itinerarios educativos, las y los jóvenes tienen que salir a poblaciones aledañas a más de diez kilómetros de distancia, lo cual implica gastos económicos que, en la mayoría de los casos, las familias radicadas en el ejido no pueden solventar. Obviamente, este contexto de precariedad no es ajeno para las poblaciones juveniles, quienes, al situarse como actores reflexivos, identifican perfectamente que la precariedad estructural y subjetiva en la que están inmersos es la causante que les impide pronunciarse con certeza sobre sí mismos (Reguillo, 2012).

En cuanto a opciones para continuar con sus intereses educativos, las personas jóvenes del ejido enfrentan esta problemática de igual manera que las poblaciones juveniles urbanas, no obstante, estas últimas tienen la oportunidad de usar estrategias públicas para mantener sus itinerarios educativos, las cuales, en la mayoría de los casos no están disponibles para las poblaciones juveniles residentes en contextos rurales. Esto se afirma en función de que no se logró documentar ningún tipo de evidencia de que las agencias gubernamentales hayan llegado con ofertas de apoyo para jóvenes en el ejido la Sierrita, lo anterior refuerza aseveraciones realizadas por investigadores que indican que "en México las políticas públicas de juventud de orden federal excluyen a las juventudes rurales" (Rossete, 2017, p. 264).

Por otro lado, las personas jóvenes habitantes en el ejido la Sierrita insertos en contextos laborales indican que el motivo por el cual no se mantuvieron estudiando radicó en que sus respectivas familias no tuvieron los recursos, principalmente económicos, para solventar los gastos necesarios. Por lo mismo, su nivel de estudio está en la mayoría de los casos, vinculado al nivel educativo ofertado en el ejido. Las reflexiones que se comparten a continuación, exponen el interés de las poblaciones juveniles en mantener sus itinerarios educativos, los cuales son coartados por el contexto de precarización en el que habitan:

Nosotras batallamos mucho con el transporte, no hay transporte para ir a la escuela. (Beatriz, 17 años)

Yo tenía pensado estudiar ingeniería en manufactura, pero pues no hubo recursos, de hecho, yo si presente hasta examen en la Politécnica de Gómez Palacio, me había quedado, pero no hubo dinero. (Germán, 21 años). 
Yo terminé la prepa (sic) pero ya no pude seguir, simplemente en el transporte uno gasta mucho porque no hay ni taxis ni camiones, yo quería estudiar pedagogía en Gómez Palacio o en Torreón. (Laura, 24 años).

A este contexto estructural y subjetivo de limitantes que enfrentan las poblaciones juveniles hay que sumarle la cultura tradicional del ejido, lo cual ocasiona que las personas jóvenes participen a partir de lo que el sistema patriarcal y adultocéntrico impone. En sus testimonios refieren que sólo pueden participar en actividades donde son convocados por algún actor colectivo con jerarquía en el ejido, cómo el Comisariado o la Asamblea Ejidal. Este aspecto que sobresale en las narrativas de las y los jóvenes es una evidencia clara de la ausencia de apertura y de procesos de integración y cohesión social hacia las personas jóvenes por parte de la estructura comunitaria ejidataria, la cual, procesa las demandas juveniles desde una mirada vertical y adultista, a partir de "lo que se nos ocurre a nosotros (personas adultas) dentro de una percepción de la construcción comunitaria" (Pacheco, 2010, p. 127).

En este marco, recuperando el análisis de Cerbino (2006) para analizar las reflexiones que los sujetos participantes aportaron, se podría decir que "la mirada" que impera en el ejido hacia sus jóvenes es de estigmatización y exclusión:

A mí sí me gusta mucho participar, pero aquí en la comunidad no hay donde participar. Me gusta ayudar mucho a la gente a organizarse. (Laura, 24 años)

A veces la gente mayor tiene otras ideas diferentes, tal vez ellos no piensan que pueden contar con uno como joven para salir adelante... Se ha visto aquí que no piden participación de los jóvenes para hacer proyectos grandes, por ejemplo, se enfocan ellos a hacerlo solos y se ve que fracasan, no da resultado y no creen que un joven pueda tener ideas para hacer crecer ese proyecto... Ellos creen que no cuenta nuestra participación. (Pedro, 24 años).

Aún y cuando se recogió una narrativa altamente cargada en torno a participar, en ayudar a la gente, y por supuesto en compartir sus opiniones e ideas, las personas jóvenes encuentran que de parte de la comunidad no hay oportunidades, ni opciones a través de las cuales pue- 
dan integrarse e intervenir en la vida pública del ejido, por tal motivo mencionan que hay una relación tensa, compleja y complicada con la gente adulta, debido a que se desvaloriza el interés de participación de las generaciones más jóvenes.

Esta reflexión crítica que realizaron las personas entrevistadas, evidencia no solamente un choque en términos generacionales, sino también un rompimiento entre estructura rural local, a la cual la población adulta se adscribe y una estructura identitaria a la que pudiéramos llamar "rural-global” o "híbrida", donde están insertas las personas jóvenes habitantes en el ejido la Sierrita. Es un choque entre la cultura parental (Feixa, 2014; Urteaga, 2010) dominante en el ejido y las políticas de las poblaciones juveniles (Feixa, 2010), que muestran su politicidad y su interés por permear la agenda del ejido con sus necesidades y exigencias. Siguiendo a Aquino \& Contreras (2016) se puede indicar que en el ejido la Sierrita se da un conflicto generacional entre sistemas de aspiraciones, esto es, procesos de tensiones y conflicto que se producen por la lucha por imponer una hegemonía de subjetividades en la comunidad.

Las narrativas de resistencia juvenil en torno al escenario donde las personas jóvenes ven limitadas sus oportunidades de participación en el ejido permitieron identificar las relaciones de poder e interés en donde desarrollan sus itinerarios, trayectorias y proyectos de vida, los cuales, en la mayoría de los casos están supeditadas a las decisiones que los propietarios de la tierra, en su mayoría hombres adultos, toman en torno al ejido. Hay narrativas que hacen referencia a qué, aún y cuando es la población no propietaria de la tierra la que mantiene "vivo" al ejido y ha apoyado fuertemente en las acciones de resistencia que se han llevado a cabo, son quienes no están integrados a las tomas de decisiones, lo cual impacta de forma negativa en los procesos de cohesión social de los diferentes grupos representados en la comunidad ${ }^{16}$; siguiendo a Reguillo (2012) en el ejido la Sierrita tenemos una inclusión desigual caracterizada por un "estar adentro", en

16 Con base en la normatividad que regula a ejidos y comunidades en México, las personas propietarias de la tierra son aquellos que tienen títulos de ejidatarios y/o comuneros, en tanto que la misma norma reconoce otras figuras como los posesionarios (los cuales, en algunos supuestos, también pueden ser titulares de derechos agrarios) y los avecindados, los cuales no son propietarios de título ejidal o comunal. 
este caso de la comunidad, pero sin tener la posibilidad de participar activamente en la toma de decisiones. Las dos reflexiones que se colocan, exponen esta idea del estar adentro pero sin posibilidad de ser reconocido en términos de igualdad.

Aquí casi siempre se manejan (los asuntos públicos) con puros ejidatarios, no toman en cuenta a los demás. Yo me llevo bien con todos, pero no hay posibilidad de participar. (Laura, 24 años).

A nosotros no nos toman en cuenta, para ellos pues son nada más ellos, su forma de pensar es muy diferente a la nuestra, ellos piensan como los de antes y uno pues sí, es de mente abierta, tiene otras opiniones que si se las expones a alguien mayor te va a zurrar ${ }^{17}$, no te va a tomar en cuenta (...) Ideas que uno proponga no te apoyarían. (Pedro, 24 años).

En este marco de resistencia comunitaria, una de las estrategias principales que diversas ONG's han impulsado en el contexto mexicano para defender los bienes naturales y fortalecer territorialidades comunitarias, es el conocimiento por parte de las comunidades de su territorio, con la intención de fortalecer organizativamente a la comunidad y delinear estrategias de desarrollo endógeno que permitan hacer frente a los supuestos "beneficios" que aportan los megaproyectos.

En esta tesitura, a las personas jóvenes del ejido la Sierrita se les consultó sobre su conocimiento en torno al Ordenamiento Comunitario Participativo que existe en su comunidad. Las respuestas que proporcionaron permiten afirmar que esta franja poblacional conoce poco los resultados del Ordenamiento, cuestión que requiere ser atendida en función del alto interés que tienen por trabajar y explotar la tierra en beneficio de la comunidad y reivindicar en términos políticos el territorio que habitan frente a actores públicos y privados, domésticos y externos que lo amenazan.

Yo sé que aquí se puede sacar provecho de explotar el cerro, sacar material, triturarlo y hacer concreto o si se llega más a fondo hacer con la sangre de grado champo y todo eso. (Germán, 21 años).

La palabra mexicana zurrar hace referencia a una llamada de atención, a un regaño que se le realiza a una persona por alguna situación específica. 
Hay mucha tierra como para sembrar, pero no se trabaja, principalmente por la falta de agua y maquinaria, no sé si tengan recursos para trabajar y pues falta organización. (Laura, 24 años).

COmo se alcanza a observar, ambas narrativas juveniles (que no fueron las únicas que se consiguieron en el mismo tenor) refieren a la posibilidad de llevar a cabo proyectos endógenos que permitirían desarrollar alternativas económicas que en el mediano plazo podrían decantar en empleos, ingresos y desarrollo local, posibilitando con esto impulsar una nueva ruralidad en el ejido la Sierrita (Arias, 2005; Fals Borda \& Mora-Osejo, 2004).

Debido a las limitantes estructurales que se viven en el ejido, la mayoría de las reflexiones de las poblaciones juveniles refieren a que en el corto plazo se miran fuera del ejido, ya que ubican que la precariedad en cuanto a las oportunidades de trabajo, de crecimiento personal, y de oportunidades de participación, les impedirá desarrollar sus intereses personales, además de que, debido a la resistencia comunitaria, a nivel local se ha generado lo que podríamos llamar marcas de resistencia, esto es, estigmas que carga la población del ejido la Sierrita, derivado del ejercicio de derechos que su comunidad ha impulsado y que, obviamente impactan en la construcción de la identidad y del sentido de pertenencia al ejido ${ }^{18}$.

Yo creo que si quiero salir adelante tengo que buscar por otros lados, en la comunidad no hay oportunidades, además nos señalan en otras comunidades. (Germán, 21 años).

Yo me veo fuera de la comunidad porque si me quedo aquí no llegaría a nada, aquí no se encuentra ninguna fuente de trabajo cercana, ni ninguna forma de apoyo que a mí me beneficiaria aquí en el ejido (...) A futuro yo me miraría fuera del ejido con un empleo estable. (Pedro, 24 años).

18 En el marco de la entrevista realizada a la Tesorera del Comisariado Ejidal en el 2016, ella mencionó que incluso cuando el ejido mantenía un plantón pacífico a las afueras de la entrada a la mina La Platosa, algunos comerciantes de la Comunidad de Bermejillo no le querían vender los artículos necesarios para alimentar a las personas que mantenían el cerco de la mina, incluso relata la mujer tesorera que la retiraron de algunos establecimientos dado que representaba a la gente que está "en contra del progreso" de la región. 
Ambas reflexiones son importantes en el sentido de que si no se lleva a cabo una reconversión en cuanto a la relevancia que tienen las poblaciones juveniles en los espacios rurales, se corre el peligro de apuntalar los desplazamientos migratorios que a la larga provocaría una desterritorialización de los territorios y con esto el debilitamiento de las territorialidades comunitarias, elemento fundamental para la defensa de la tierra y territorio en el marco del reconfiguración territorial que lleva a cabo el modelo neoliberal.

En este tenor, algunas de las personas jóvenes que participaron en las entrevistas han enfrentado procesos de migración interna, esto principalmente para buscar oportunidades laborales. No obstante, dichos procesos migratorios no han alcanzado a generar las condiciones para cumplir los objetivos por las cuales se realizó el desplazamiento, hecho por el cual, quienes han migrado han tenido que regresar a su comunidad de origen.

Los motivos más importantes que han dado pie a los procesos de migración en jóvenes en el ejido la Sierrita son: (a) seguir estudiando, esto en función de que para mantener los itinerarios educativos después del nivel secundario se tiene que ir a otras comunidades para acceder al siguiente nivel educativo ${ }^{19}$; (b) si se quiere conseguir un empleo también hay que salir de la comunidad, generar procesos de movilidad geográfica para buscar mejores condiciones de vida (Solís, 2014), las cuales en el ejido no se encuentran. Este último aspecto es relevante debido a que los empleos que comúnmente son ofertados a las poblaciones juveniles en la zona son empleos precarios, esto es, son los de más baja calidad, inestables, con poca o nula proyección a futuro y con escasos niveles de protección social (Solís \& Castañeda, 2013).

Un elemento que sobresale en la narrativa de las personas jóvenes entrevistadas refiere al conflicto que el ejido tiene en contra de la minera canadiense Excellon. La narrativa refiere a que, aún y cuando han participado en varias acciones colectivas llevadas a cabo dentro del marco de la resistencia comunitaria contra las prácticas de despojo de la empresa minera, no conocen a fondo el conflicto, por tal motivo sus

19 Con base en los testimonios, hay casos exitosos de jóvenes del ejido la Sierrita que han salido de la comunidad agraria para mantener sus trayectorias educativas. 
opiniones son ambivalente, en función de que algunos de estos jóvenes fueron favorecidos de alguna u otra manera por los beneficios que la empresa proporcionó, en algún momento, a la comunidad.

No obstante que la opinión de algunos de las y los jóvenes es ambigua en torno al conflicto, tienen mucha claridad y a la vez comparten el posicionamiento político de las personas titulares de los derechos agrarios del ejido respecto a que están ejerciendo, de manera legal, legítima y de forma correcta su derecho al control de sus recursos naturales.

A partir de lo anterior, el posicionamiento político que se encuentra en las personas jóvenes descansa en observar que las prácticas que está llevando a cabo la minera canadiense impactan de forma negativa a la comunidad y al ejido, por tal motivo, para las poblaciones juveniles abordadas, con los recursos que se están extrayendo de su territorio, bien se podrían generar opciones para que el ejido pudiera crecer en términos comunitarios, de infraestructura y potenciar proyectos de desarrollo comunitario.

Dentro de este marco, uno de los aspectos en donde mayor atención se puso con las personas jóvenes participantes, radicó en conocer, a partir de sus propias narrativas, la experiencia y vivencia que han tenido relacionada a la resistencia que el ejido mantiene. En este sentido, se puede decir que han participado (de forma separada) en todas y cada una de las acciones de resistencia que el ejido ha llevado a cabo, esto es: (1) los plantones pacíficos que se han impulsado; (2) las marchas que se han emprendido para evidenciar las inconsistencias narrativas y prácticas de la minera y la falta de justicia de las autoridades correspondientes, y por supuesto; (3) las concentraciones que se han realizado en diferentes instancias públicas judiciales para presionar a que las instituciones impartidoras de justicia dicten sentencias apegadas a los estándares más altos de derechos humanos.

Estas participaciones juveniles en las distintas actividades de resistencia no han sido sólo de una vez, sino que su intervención, ha sido de forma continua en cuando menos un periodo de cinco años; esto permite argumentar qué, aún y cuando esta resistencia comunitaria no ha sido para reivindicar de forma directa algún tipo de exigencia de las poblaciones juveniles, si ha servido para forjar en las personas jóvenes subjetividades que permiten identificar el contexto de exclusión 
en el cual se encuentran, exigir el respeto a sus derechos y cuestionar identidades asignadas por el poder hegemónico (García-García, 2018).

La participación que tienen las poblaciones juveniles en la resistencia que el ejido ha llevado por el control de sus recursos naturales y por la defensa de su territorio, ha permitido que se constituyan resistencias juveniles al interior de la comunidad, que si bien no son identificadas de forma autónoma y preponderante, si han permitido un agenciamiento (que por el momento no ha logrado impactar en las estructuras patriarcales y adultocentricas que caracterizan al ejido) de las personas jóvenes en torno a su condición de población excluida y discriminada. Las reflexiones que a continuación se recuperan, dan cuenta de las diferentes formas en las que las poblaciones juveniles han participado para apoyar y canalizar sus recursos en la resistencia de su comunidad:

A mí me tocó participar en los plantones, yo estaba en el Sindicato, y apoyábamos al ejido, fuimos a las marchas, nos fuimos hasta Durango... Yo trabajaba en la mina, y cuando exigimos nuestros derechos nos quedamos sin trabajo... Pero sabemos que el gobierno siempre está con quien tiene dinero. (Laura, 24 años).

Apoyé un poco en el plantón y también en las marchas que partían de ahí de la entrada de la mina hacia Bermejillo. En ese tiempo yo tenía 17 años. Yo iba a apoyar a los ejidatarios, porque mi apá (sic) es uno de ellos. (Germán, 21 años).

Yo estuve la mayor parte del plantón, estuve ahí, cuando se me hizo más pesado me regresaba, pero también participé en las marchas. (Fátima, 25 años).

Para mí fue algo confuso, porque yo iba a apoyar a mi mamá y a mi papá al plantón y cuando iba con ellos no eran grandes las comodidades, era muy difícil vivir allí, pero yo quería apoyar. (Pedro, 24 años).

Con estas narrativas de resistencia que se recuperan, se puede observar que la participación política de las poblaciones juveniles es alta, esto a su vez les ha permitido ser críticos de las políticas de desterritorialización y reordenamiento territorial que llevaron a cabo los gobiernos neoliberales en México en beneficio del patrón de acumulación capitalista actual. Así mismo permiten observar los recursos que como 
jóvenes aportaban a la resistencia, los cuales no sólo deben ser analizados en sentido objetivo (su presencia como tal), sino en aspectos de corte simbólico (fortalecimiento de la comunidad en términos intergeneracionales) y subjetivo (apoyo familiar y comunitario) respecto a sus pares adultos.

En cuanto al interés por trabajar y defender el territorio, aún y cuando ninguno de las y los jóvenes es titular de la tierra, sí se muestran altamente interesados en ser reconocidos como ejidatarios, condición que les permitiría no solamente ser propietarios de las tierras sino también: (1) poder opinar y participar en la toma de decisión del núcleo agrario; (2) trabajar y sembrar las tierras para beneficio familiar; (3) cuidar las tierras y el territorio en donde nacieron; (4) sembrar y sacar el mayor provecho a las tierras que conforman el ejido.

Con estos posicionamientos, lo que se observa es que las poblaciones juveniles en el ejido la Sierrita buscan cuestionar los procesos de desterritorialización simbólica y objetiva (Giraldo, 2015) que empresas y gobiernos neoliberales buscan apuntalar para favorecer los procesos de despojo múltiple a los que están expuestas comunidades y ejidos en México.

La posición que tienen las poblaciones juveniles por recuperar el trabajo con la tierra permite argumentar qué, conceptualizan está actividad desde una posición política que reivindica la relevancia del contexto agrario en un momento en donde a nivel nacional por más de treinta años se olvidó de forma intencional el apoyo al campo ${ }^{20}$.

A mí sí me gustaría ser ejidatario para pelear lo que ahorita está en conflicto y creo que tenemos nuevas ideas y más propósitos y creo que somos los jóvenes los que podríamos defender nuestras tierras. (Germán, 21 años).

A mí me gustaría ser ejidataria, así tendría más derecho a opinar, podría trabajar las tierras, además nací aquí. (Laura, 24 años).

$20 \quad$ La actual administración federal en México ha impulsado una serie de estrategias de primer nivel para apoyar e impulsar el desarrollo en el campo mexicano, pero aún es poco tiempo para realizar una evaluación de los programas federales enfocados a este sector de la población. 
En este marco de condiciones complejas y complicadas tanto estructurales como simbólicas, es que las poblaciones juveniles habitantes del ejido la Sierrita tratan de construir sus biografías, trayectorias e itinerarios de vida, los cuales, como se ha observado, están atravesados por una serie de factores poco beneficiosos para esta población etaria. A partir de lo anterior, las personas jóvenes participantes en este ejercicio diagnóstico fueron desarrollando diferentes proyectos de vida, los cuales, lamentablemente, poco tuvieron que ver con un proyecto colectivo comunitario, ya que no lograron ser integrados por la comunidad $^{21}$, la cual a final de cuentas mantiene su resistencia agraria en contra de la empresa minera canadiense Excellon.

\section{Conclusiones}

Frente al contexto de reconfiguración territorial y de despojo múltiple que caracteriza al modelo neoliberal extractivista, las comunidades agrarias que se encuentran en procesos de exigibilidad de derechos por el control de sus recursos naturales requieren, antes que nada, fortalecerse, cohesionarse y por supuesto, organizarse a nivel interno para hacer frente a las afrentas que no solamente provienen de las empresas que impulsan los megaproyectos, sino también de las autoridades públicas, las cuales en muchos de los casos, operan y despliegan todo su poder y conocimiento en detrimento de las comunidad ${ }^{22}$.

El caso del ejido la Sierrita permite observar que la organización comunitaria ha sido un elemento fundamental para mantener una resistencia agraria destacable ante una empresa minera transnacional; no obstante, frente a la fortaleza comunitaria evidenciada en más de diez años de resistencia, también es importante destacar las limitantes y obstáculos que se pueden observar, con la intención de atenderlas y por supuesto, buscar soluciones a través de la misma acción comunitaria.

\footnotetext{
${ }^{21}$ A partir de visitas posteriores al ejido la Sierrita en los años 2017 y 2018 es que se logró observar que las personas jóvenes participantes en este ejercicio no pudieron conseguir la meta de ser integrados en la toma de decisiones del ejido, por ende, emprendieron otros proyectos de manera particular e independiente.

22 En el Informe La Jurisdicción agraria y los derechos humanos de los pueblos indígenas y campesinos en México (Torres-Mazuera, Fernández, \& Gómez, 2018) se puede observar de qué manera las autoridades agrarias, que en teoría deberían servir para apoyar, acompañar y fortalecer la propiedad social de la tierra, sirven para debilitarla y generar conflictos al interior de las mismas, con el objetivo final de beneficiar a actores particulares y colectivos que buscan apropiarse de amplias franjas de territorios.
} 
En este tenor, el artículo, a partir de recuperar la voz de las poblaciones juveniles, permitió evidenciar que para el caso del ejido la Sierrita hay una franja poblacional que fue poco aprovechada para fortalecer y reanimar la resistencia agraria. Los argumentos expuestos basados en las narrativas de resistencia de poblaciones juveniles dejan ver que las estructuras agrarias, para el caso bajo estudio, requieren tener la capacidad de incluir e integrar a aquellas personas que en estos momentos no son propietarios de la tierra, pero que en algún momento pueden llegar a serlo y que además están interesado en impulsador proyectos endógenos comunitarios.

Pero más allá de lo anterior, se evidenció que aún y cuando el ejido la Sierrita está inserto en una dinámica de exigibilidad de derechos por el control de sus recursos naturales, al interior de esta comunidad se transgreden derechos de una población particular, esto es, de las personas jóvenes ${ }^{23}$, los cuales no encuentran mecanismos formales y pertinentes para poder integrarse plenamente a los procesos y prácticas de producción y reproducción social comunitaria.

Las narrativas de resistencia expuestas permiten concluir que la condición de juventud que las personas jóvenes enfrentan en el ejido la Sierrita es altamente intrincada en función de que aún y cuando muestran una politicidad que va en aumento y un interés en participar en los asuntos públicos de la comunidad agraria, tienen que replegarse y alinearse a los dictados que la cultura tradicional del ejido sigue imponiendo y reproduciendo de manera estructural, esto a final de cuentas, permitió exponer diversas facetas de la exclusión a la que están inmersos y a la vez evidenciar la tensión y el conflicto del sistema de aspiraciones de dos generaciones, que deberían conciliar intereses y estrategias de lucha para enfrentar los procesos de despojo territorial y los procesos de desterritorialización simbólica que se busca imponer en comunidades y ejidos.

\footnotetext{
23 Al utilizar la perspectiva de género, también se logró observar que las mujeres son otra franja poblacional que se encuentra excluida, ya que las mujeres ejidatarias, que por ende tienen derechos respecto a la tierra y las decisiones, no representa ni el veinte por ciento del total de titulares de derechos agrarios en el ejido la Sierrita. Esta situación es un reflejo de la condición que enfrentan las mujeres respecto a la propiedad de la tierra, ya que, con base en información del Registro Agrario Nacional, las mujeres ejidatarias y comuneras sólo representan el $22.5 \%$ del total de personas con derechos agrarios en México (Gobierno de México, 2020).
} 


\section{Recomendaciones}

A modo de lista, expongo algunas recomendaciones que observo a partir de las narrativas de resistencia que las personas jóvenes participantes en este ejercicio compartieron y que, desde mi punto de vista, podrían ser relevantes para fortalecer y reanimar otras resistencias que pueblos y comunidades llevan a cabo contra el capital doméstico e internacional que busca apropiarse por todos los medios de los territorios y los recursos naturales que existen en los mismos. Es importante mencionar que dichas recomendaciones requieren ser revisadas, analizadas y cuestionadas a partir de las visiones propias de las comunidades y las resistencias en turno, esto con la intención de valorar su pertinencia.

- Eliminar las estructuras patriarcales y adultocéntricas que limitan y deslegitiman la participación de las poblaciones juveniles en las resistencias. Para enfrentar el acotamiento y el desdibujamiento de la participación juvenil es recomendable modificar las lógicas de mandatos de género y control adultista que siguen imperando en las resistencias y por supuesto, a nivel estructural, en las relaciones sociales. Sería enriquecedor que las resistencias comunitarias y agrarias, construyan con paciencia el relevo generacional, que permita mantener las reivindicaciones de ejercicio de derechos en contextos donde los procesos de lucha son largos y complicados.

- A la par de mantener las prioridades de exigibilidad de derechos en el marco de las resistencias, sería oportuno impulsar estrategias de desarrollo endógeno en las comunidades o ejidos para asegurar la permanencia y ocupación de las poblaciones juveniles en sus territorios y así evitar los desplazamientos y la despoblación de la propiedad social. Aquí cobran relevancias las estrategias encaminadas a que las poblaciones juveniles se apropien objetiva y simbólicamente de sus territorios, saberes y culturas, con lo anterior se pueden contrarrestar los procesos de desterritorialización y la transformación forzada de modos de vida comunitaria que impulsa el capital doméstico e internacional sobre territorios de ejidos y comunidades.

- Considerar reconocer la participación y las vocerías de las poblaciones juveniles con la intención de potenciar la representatividad y visibilización de esta franja poblacional en las resistencias. Los procesos de resistencia y exigibilidad de derechos son largos, por lo mismo sería útil la incorporación de mujeres y hombres jóvenes a los grupos 
de representantes y voceros de las resistencias. Esto no sólo permitiría la integración de poblaciones juveniles a los espacios de toma de decisión de las resistencias, sino también la integración de sus propuestas y la exposición pública de su participación.

- Para el caso mexicano, integrar a mujeres y hombres jóvenes a los procesos de titularidad y tenencia de la tierra, con la intención de fortalecer tanto la propiedad social, el núcleo comunitario (ejido o comunidad) y la apropiación del territorio por parte de las y los jóvenes rurales e indígenas. Con esta acción, en el mediano plazo se podría paliar el contexto de despojo, exclusión y vulnerabilidad que mujeres y jóvenes enfrentan en los núcleos agrarios, ya que, al ser propietarios de tierras, no estarían a merced de la decisión del varón adulto propietario de la titularidad de la tierra, que en no pocos casos, ha sido cooptado o tiene una colaboración cercana con quienes impulsan los procesos de despojo de territorios.

\section{Referencias}

Ancheita, A. (2013). Constructing Alliances to Defend Dignity! Miners and communitywork together in northern Mexico. Progressive Planning. The magazine of Planners Network, Fall(197), 43-45.

Aquino-Moreschi, A., \& Contreras-Pastrana, I. (2016). Comunidad, jóvenes y generación. Disputando subjetividades en la Sierra Norte de Oaxaca. Revista Latinoamericana de Ciencias Sociales, Niñez y Juventud, 14(1), 463-475.

Arias, P. (2005). Nueva ruralidad: antropólogos y geógrafos frente al campo hoy. En H. Ávila Sánchez, Lo urbano-rural, ¿nuevas expresiones territoriales? (pp. 123-159). Cuernavaca: Centro Regional de Investigación Multidisciplinarias/UNAM.

Bartra, A. (2016). En el torbellino mexicano. Movimientos campesinos al alba del tercer milenio. Textual. Análisis del medio rural latinoamericano, 9-34.

Cámara de Diputados. (11 de agosto de 2014). Ley Minera. Recuperado el 29 de enero de 2017 de http://www.diputados.gob.mx/LeyesBiblio/pdf/151_110814.pdf

Cámara de Diputados. (19 de diciembre de 2016). Ley Agraria. Recuperado el 24 de enero de 2017 de http://www.diputados.gob. mx/LeyesBiblio/pdf/13_191216.pdf 
Cámara Minera de México. (2015). Mapa de Indicadores Mineros 2015. Recuperado el 25 de enero de 2017 de https://camimex.org. $\mathrm{mx} /$ index.php/mapa_nacional/

Castro, M., Rojas, G., \& Ruiz, C. (2008). La juventud indígena en Chile: Expectativas y demandas. En M. L. Pérez, Jóvenes indígenas y globalización en América Latina (pp. 93-112). México D.F.: INAH.

Cerbino, M. (2006). Jóvenes en la calle. Cultura y conflicto. Barcelona: Anthropos.

Corte, V. (2015). Resistencias juveniles en escenarios locales. El caso del No al Dragado, en una ciudad puerto, Argentina. En A. Nateras, G. Medina, \& M. Sepúlveda (Coords.), Escrituras emergentes de las juventudes latinoamericanas (pp. 99-126). México D.F: Gedisa.

Dirven, M. (2016). Juventud rural y empleo decente en América Latina. Santiago de Chile: Organización de las Naciones Unidas para la Alimentación y la Agricultura.

Fals Borda, O. \& Mora-Osejo, L. (2004). La superación del Eurocentrismo. Enriquecimiento del saber sistémico y endógeno sobre nuestro contexto tropical. Polis, Revista Latinoamericana, 2(7).

Feixa, C. (2010). El imperio de los jóvenes. En S. V. Alvarado \& P. Vommaro (Eds.), Jóvenes, cultura y política en América Latina: Algunos trayectos de sus relaciones, experiencias y lecturas (1960-2000) (pp. 13-20). Buenos Aires: Homo Sapiens.

Feixa, C. (2014). De la generación @, a la \# generación. Barcelona: Ned Ediciones.

García-García, V. D. (2018). La seguridad en disputa: divergencias y contradicciones en torno al concepto. Revista Cambios y Permanencias, 9(1), 143-165.

Giraldo, O. F. (2015). Agroextractivismo y acaparamiento de tierras en América Latina: una lectura desde la ecología política. Revista Mexicana de Sociología, 77(4 ), 637-662.

Gobierno de México. (1 de febrero de 2020). Creciente participación de las mujeres como sujetos de derechos: RAN. Recuperado de https://www.gob.mx/ran/prensa/creciente-participacionde-las-mujeres-como-sujeto-de-derechos-ran-93541

Jurado, C., \& Tobasura, I. (2012). Dilema de la juventud en territorios rurales de Colombia: ¿campo o ciudad? Revista Latinoamericana de Ciencias Sociales, Niñez y Juventud, 10(1), 63-77. 
Kessler, G. (2005). Estado del arte de la investigación sobre juventud rural en América Latina. Buenos Aires: EHESS-UNGS.

López Barcenas, F. (2017). El régimen de la propiedad agraría en México. Primeros auxilios jurídicos para la defensa de la tierra y los recursos naturales. México D.F: Centro de Orientación y Asesoría a Pueblos Indígenas A.C., Centro de Estudios para el Cambio en el Campo Mexicano, Instituto Mexicano para el Desarrollo Comunitario A.C., Servicios para una Educación Alternativa EDUCA A.C.

López de la Vega, M. (2016). Comunidades Ixiles y Estado en Guatemala: Entre la lucha y el despojo. En M. Rosales, G. Zenaida \& P. Carla (Eds.), Postextractivismo y crecimiento en América Latina. Historias, problemas y desafíos hacia una agenda de luchas comunes (pp. 237-253). Buenos Aires: CLACSO.

Makowski, S. (2010). Jóvenes que viven en la calle. México D.F: Siglo XXI, UAM Iztapalapa.

Medina, P., Urteaga, M., \& Bonilla, L. (2013). Los Guaches de la tierra caliente de Guerrero: Configuraciones de los juvenil en un espacio rural. En L. Pacheco, R. Román, \& M. Urteaga (Coords.), Jóvenes rurales. Viejos dilemas, nuevas realidades (pp. 31-73). México D.F.: Juan Pablos Editor.

Minería en línea. (30 de julio de 2018). Excellon Resources aumenta $120 \%$ producción de plata en México. Recuperado de https://mineriaenlinea.com/2018/07/excellon-resourcesaumenta-120-produccion-de-plata-en-mexico/

Moore, J. (2012). Las entrañas de la complicidad canadiense: Excellon Resources, la Embajada de Canadá y la violación de los derechos laborales y territoriales en Durango, México. México D.F.: MiningWatch Canadá y United Steelworkers.

Navarro, M. (2015). Luchas por lo común. Antagonismo social contra el despojo capitalista de los bienes naturales en México. México D.F.: Bajo Tierra Ediciones.

Pacheco, L. (2010). Los últimos guardianes. Jóvenes rurales e indígenas. En R. Reguillo (Coord.), Los jóvenes en México (pp. 124153). México D.F.: Fondo de Cultura Económica y Consejo Nacional para la Cultura y las Artes.

Peña, J. (19 de enero de 2020). Lo que la minera se llevó. Recuperado el 13 de febrero de 2020 de https://vanguardia.com.mx/articulo/lo-que-la-minera-se-llevo 
Perea, C. M. (2009). Comunidad y resistencia. Poder en lo local urbano. En G. Medina (Ed.), Juventud, territorios de identidad y tecnología (pp. 189-234). México D.F.: Universidad Autónoma de la Ciudad de México.

Pérez, M. L. (2015). Ser joven y ser maya en un mundo globalizado. México D.F.: Instituto Nacional de Antropología e Historia.

Proyecto de Derechos Económicos, Sociales y Culturales. (2013). Ejido "La Sierrita" unión contra los abusos. En Red Nacional de Organismos Civiles de DH, Acompañando la esperanza: 20 experiencias en defensa y promoción de los derechos humanos (pp. 181-191). México D.F: Red TDT.

Proyecto de Derechos Económicos, Sociales y Culturales. (2015). La Sierrita de Galeana, una historia de lucha (video). Recuperado el 23 de enero de 2017 de https://www.youtube.com/ watch?v=QMrSdpSSQYk

Registro Agrario Nacional. (2017). Padron e Historial de Núcleos Agrarios. Recuperado el 24 de enero de 2017 de http://phina.ran. gob.mx/phina2/

Reguillo, R. (2012). Culturas Juveniles. Formas políticas del desencanto. México D.F.: Siglo XXI.

Rendón, J. J. (2011). Taller de diálogo cultural. Metodología participativa para estudiar, diagnósticar y desarrollar las culturas de nuestros pueblos. México D.F: Centro de Estudios Antropológicos, Científicos, Artísticos, Tradicionales y Lingüisticos Ce-Acatl.

Reyes, E. (2015). Estrategias campesinas. El papel de la juventud rural en la reproducción agrícola del maíz en San Juan Atenco, Puebla. En Nuevos métodos para nuevas realidades. Segundo encuentro nacional de jóvenes que investigan jóvenes (pp. 33-46). México D.F: Seminario de Investigación en Juventud, UNAM.

RompevientoTV. (2012). La lucha del ejido La Sierrita, Durango, contra una empresa minera (video). Recuperado el 23 de enero de 2017 de https://www.youtube.com/ watch?v=00OWbgB0Vwc

Rossete, J. C. (2017). Políticas públicas para las juventudes rurales en México. Un abordaje desde la construcción social de población objetivo. Tesis de Maestría en Trabajo Social. México D.F.: ENTS-UNAM. 
Suprema Corte de Justicia de la Nación. (2014). Protocolo de actuación para quienes imparten justicia en casos relacionados con proyectos de desarrollo e infraestructura. México D.F.: Suprema Corte de Justicia de la Nación.

Servicio Geológico Mexicano. (2015). Datos económicos y proyectos mineros en Durango, México. Recuperado el 23 de enero de 2017 de http://portalweb.sgm.gob.mx/economia/es/mineria-en-mexico/375-durango.html

Solís, M. (2014). La precarización del trabajo desde una perspectiva sociocultural en un contexto fronterizo. Región y Sociedad, 26(59), 81-112.

Solís, M., \& Castañeda, M. (2013). Jóvenes en la confección: trayectorias laborales y expectativas de vida en la frontera. En M. Baraja, \& M. Solís (Eds.), Fronteras comparadas: desarrollo, trabajo y migración (pp. 87-117). México D.F: El Colegio de la Frontera Norte.

Soliz, F., \& Maldonado, A. (2012). Guía de metodología comunitarias participativas. Quito: Clínica Ambiental.

Torres-Mazuera, G., Fernández, J., \& Gómez, C. (2018). La jurisdicción agraria y los derechos humanos de los pueblos indigenas y campesinos en México. S/I: Fundación para el Debido Proceso.

Urteaga, M. (2010). Género, clase y etnia. Los modos de ser joven. En R. Reguillo (Coord.), Los jóvenes en México (pp. 15-51). México D.F.: Fondo de Cultura Económica y Consejo Nacional para la Cultura y las Artes.

Vargas, S. (2016). Constelación narrativa de resistencia. Jóvenes hijos de trabajadores agrícolas en la frontera Méxco-Estados Unidos. Norteamérica, 11(1), 43-73.

Vigil, J. D. (2013). Marginalidad múltiple: un marco comparativo para comprender a las pandillas. En J. M. Valenzuela, A. Nateras, \& R. Reguillo (Eds.), Las Maras. Identidades juveniles al límite (pp. 63-81). México D.F.: UAM, COLEF, Juan Pablos Editor. 